\title{
Mediation of inventory control practices in proficiency and organizational performance: State- funded hospital perspective
}

\author{
Aamir Rashid Hashmi ${ }^{a}$, Noor Aina Amirah ${ }^{b^{*}}$, Yusnita Yusof ${ }^{b}$ and Tengku Noor Zaliha ${ }^{b}$
}

${ }^{a}$ Faculty of Business Administration, Iqra University, Main Campus, Defense View, Kararchi, Pakistan

${ }^{b}$ Faculty of Business and Management, Universiti Sultan Zainal Abidin, Gong Badak, Kuala Terengganu, 21300, Malaysia

\section{H R O N I C L E}

Article history:

Received September 2, 2020

Received in revised format

October 18,2020

Accepted November 142020

Available online

November 142020

Keywords:

AMOS

SEM

Inventory management

CFA

Mediation

Structural Equation Modeling

Proficiency

\section{A B S T R A C T}

\begin{abstract}
The organizational performance at public hospitals differs from the corporate sector and faces maladministration. Further, performance at public hospitals is crucial as it directly affects human lives and endeavors for accessibility to medicines and equipment. This research is designed to determine the mediating role of inventory control practices in proficiency and organizational performance at public hospitals. This paper uses a quantitative research with a survey method using multistage cluster sampling which was performed on a sample size of 200. Exploratory Factor Analysis and Confirmatory Factor Analysis validated the model for Structural Equation Modeling. The findings of this research indicate a significant positive effect and full mediation of inventory control practices between the study variables. Further, the significance indicated that competent and well-trained staff manages inventory efficiently for improved organizational performance through better service quality and reduced cost. An integrated second-order model of this research will benefit the public hospitals, healthcare industry at large, organizations managing mega structured inventory, and to the body of knowledge.
\end{abstract}

(C) 2021 by the authors; license Growing Science, Canada.

\section{Introduction}

State-funded hospitals are crucial entities due to the involvement of multiple stakeholders like broader public, government, clinicians, and the patients (Hashmi, Amirah, \& Yusof, 2020a). Thereby, these are usually alleged and criticized for maladministration and inadequate accountability (Rashid, 2020; Andrews et al., 2019). In budget 2020-21, the Department of Health, Punjab allocated 282.2 out of 7,137 billion Pakistani Rupees for healthcare. Despite the colossal amount, the uprising mortality rate of under five years is 112 per 1000,77 per 1000 for infants, and 300 per 100,000 for maternal mortalities, which is a frightening figure. Rashid and Amirah (2017) found stock-outs, expired batches, and hasty buying of curative medicines at different healthcare facilities of Punjab. Later, in the world healthcare, the ranking of at $122^{\text {nd }}$ position indicates the worseness (Rashid, 2020). Because of the lifesaving drugs and the decisive issues, the public hospitals necessitate an empirical finding for mediation of inventory control practices (ICP), and the effect of proficiency on organizational performance (OP).

\subsection{Research Question and Objectives}

The research question will explore the important role of proficiency, mediation of ICP, and OP at public hospital. Meanwhile, the following objectives will ponder upon the problem statement:

1. Determine the effect of proficiency on ICP.

* Corresponding author

E-mail address: ainaamirah@unisza.edu.my (N. A. Amirah)

C 2021 by the authors; licensee Growing Science.

doi: $10.5267 /$ j.uscm. 2020.11 .006 
2. Determine the effect of proficiency on OP.

3. Determine the effect of ICP on OP.

4. Determine the mediation effect of ICP between proficiency and OP.

\section{Theoretical framework}

A quantitative method was utilized to evaluate the variables: proficiency, ICP mediator, and OP (Creswell, 2014). Then, resource-based view (RBV) theory was espoused to examine the hypothesized relationships. The RBV theory determines the divergence in performance and resources at an organizational level, especially those capabilities and resources that are viable and helps to enhance efficiency (Shibin, Gunasekaran, \& Dubey, 2017). According to Wernerfelt (1984), viable resources involve capital, employee knowledge, effective processes and procedures, and technology. In fact, Hashmi et al. (2020b) proved that proficiency improves processes and indirectly adds significance to an organization. Consequently, RBV theory presents an adequate theoretical framework, as Hashmi et al. (2020b) already confirmed the resource synergy in association with inventory control and organizational performance.

\section{Literature review}

Inventory control is pivotal and requires managerial oversight as it involves immense capital and affects performance at every organization (Samuel \& Ondiek, 2014). According to Pritchard, Gracy, and Godwin (2010), performance can be augmented through monitoring operational expenses, reducing costs, and increasing value. Besides, efficiency, costeffectiveness, and economies of scale are indispensable in a viable milieu. In such situation, ICP offer an efficient and persistent supply of inventories (Rashid, 2016), while, the breakdown in functional units of inventory control ruins the performance (Shah \& Shin, 2007; Rehman et al., 2019). However, Hashmi et al. (2020b) empirically instigated that the proficiency greatly enhances production, scheduling, and planning, and thus eliminate shortages and enhance stock availability. Attom (2013) believes that more considerations are being paid to enhance proficiency in benefits for organizations. Consequently, Fig. 1 depicts a conceptual framework that is based on RBV theory and the relevant literature. There is one independent construct (proficiency), one mediator (ICP) to examine the mediation, and one dependent construct (OP).

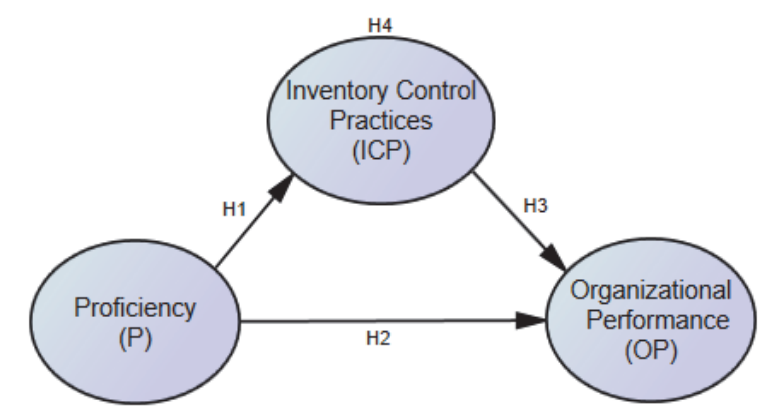

Source: Graphics of AMOS

Fig. 1. Conceptual framework

\subsection{Research Hypotheses}

The conceptual framework helps in developing the study hypotheses to test the study variables. The hypotheses are as below:

$\mathrm{H}_{1}$ : Proficiency has a positive effect on ICP.
$\mathrm{H}_{2}$ : Proficiency has a positive effect on OP.
$\mathrm{H}_{3}$ : ICP has a positive effect on OP.
$\mathrm{H}_{4}$ : ICP mediates the relationship between proficiency and OP.

\section{Data and findings}

Positivist research paradigm is utilized for quantitative method to perform survey on interval scale (Creswell, 2014). Further, a questionnaire on three variables through a 5-point Likert scale was administered, to validate a second-order construct model by performing Exploratory Factor Analysis (EFA) and Confirmatory Factor Analysis (CFA) through 
IBM $^{\circledR}$ SPSS $^{\circledR}$ V22.0 and IBM ${ }^{\circledR}$ SPSS $^{\circledR}$ AMOS $^{\text {TM }} 22$, respectively. According to Worthington and Whittaker (2006), EFA and CFA are procedures of scale validation but on different sample sizes. Hence, random selection of 100 respondents was made for EFA (Hair et al., 2010), While, multistage cluster sampling was used to reach a suitable sampling frame and to determine an adequate sample size for CFA (Hashmi et al., 2020a). Total listed population of 2,899 hospitals were clustered into nine divisions then one district of each division was taken and 343 hospitals constituted sampling frame to draw a sample size. According to Hair et al. (2010), an appropriate sample size relies on multiple factors. But a sample of 200 is adequate when using AMOS for SEM analysis (Awang, 2015). Therefore, 200 inventory managers from different hospitals were randomly selected.

\subsection{Exploratory Factor Analysis (EFA)}

Principle axis factoring in orthogonal rotation (varimax) was used on 27 items; orthogonal rotation considers the resultant factors are un-correlated to each other. Further, the number of factors was extracted by setting eigenvalues at one (Hair et al., 2010). Table 1 shown the summarized EFA results with EFA assumptions below:

- $\quad$ Table 1 shows the Kaiser-Meyer-Olkin (KMO) value for proficiency (0.842), ICP (0.852), and OP (0.809), which is acceptable $(>0.60)$, with significant $p$ value $(<0.001)$ for Bartlett's test of sphericity (Field, 2013; Rashid, Amirah, \& Yusof, 2019),

- Communalities were $>0.2$ for each item of its variable except P7 of proficiency, which will signify an additional factor. Thereby, P7 was deleted by re-running the analysis (Hashmi et al., 2020b),

- Total variance explained for first factor was less than 50 percent and greater than 60 percent for second factor of each construct (Rashid et al., 2019),

- $\quad$ The summarized rotated factor matrix results are shown from highest to lowest factor loadings. Here, OP7 and OP5 with factor loadings less than 0.60, these items were deleted simultaneously and the analysis was re-run (Awang, 2015),

- Finally, based on the extracted factors in EFA, the factors were renamed appropriately and 24 retained items were carried forward to perform CFA procedure.

Table 1

Summarized EFA results

\begin{tabular}{|c|c|c|c|c|c|c|c|c|c|}
\hline \multirow{3}{*}{ Variables } & \multirow{3}{*}{ КМO } & \multirow{3}{*}{ Items } & \multirow{3}{*}{ Communalities } & \multicolumn{6}{|c|}{ Factors } \\
\hline & & & & \multicolumn{2}{|c|}{ Proficiency } & \multicolumn{2}{|c|}{ ICP } & \multicolumn{2}{|c|}{ OP } \\
\hline & & & & 1 & 2 & 1 & 2 & 1 & 2 \\
\hline \multirow{8}{*}{ 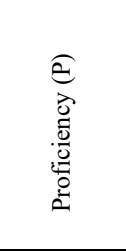 } & \multirow{8}{*}{0.842} & $\mathrm{P} 1$ & 0.688 & 0.825 & & & & & \\
\hline & & $\mathrm{P} 4$ & 0.665 & 0.800 & & & & & \\
\hline & & $\mathrm{P} 2$ & 0.595 & 0.743 & & & & & \\
\hline & & P3 & 0.453 & 0.659 & & & & & \\
\hline & & P8 & 0.704 & & 0.764 & & & & \\
\hline & & P5 & 0.605 & & 0.753 & & & & \\
\hline & & P6 & 0.622 & & 0.705 & & & & \\
\hline & & $\mathrm{P} 7$ & 0.112 & & & & & & \\
\hline \multirow{8}{*}{ 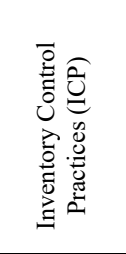 } & \multirow{8}{*}{0.852} & ICP2 & 0.742 & & & 0.825 & & & \\
\hline & & ICP1 & 0.656 & & & 0.808 & & & \\
\hline & & ICP4 & 0.661 & & & 0.791 & & & \\
\hline & & ICP3 & 0.493 & & & 0.655 & & & \\
\hline & & ICP7 & 0.606 & & & & 0.778 & & \\
\hline & & ICP6 & 0.592 & & & & 0.727 & & \\
\hline & & ICP5 & 0.532 & & & & 0.713 & & \\
\hline & & ICP8 & 0.551 & & & & 0.678 & & \\
\hline \multirow{11}{*}{ 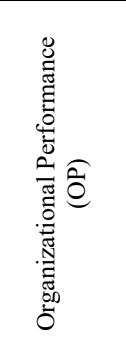 } & \multirow{11}{*}{0.809} & OP9 & 0.722 & & & & & 0.949 & \\
\hline & & OP8 & 0.734 & & & & & 0.887 & \\
\hline & & OP10 & 0.573 & & & & & 0.816 & \\
\hline & & OP11 & 0.576 & & & & & 0.759 & \\
\hline & & OP7 & 0.497 & & & & & 0.470 & \\
\hline & & OP6 & 0.274 & & & & & & 0.846 \\
\hline & & OP3 & 0.952 & & & & & & 0.834 \\
\hline & & OP4 & 0.806 & & & & & & 0.750 \\
\hline & & $\mathrm{OP} 2$ & 0.721 & & & & & & 0.746 \\
\hline & & OP1 & 0.596 & & & & & & 0.698 \\
\hline & & OP5 & 0.221 & & & & & & 0.491 \\
\hline
\end{tabular}




\subsection{Demographic Attributes}

Demographic attributes shown in Table 2 described: few were female (17, 8.5\%), with almost all male (183, 91.5\%); a far smaller proportion was married $(46,23 \%)$ than single $(154,77 \%) ; 141(70.5 \%)$ aged $20-30$ years, while $51(25.5 \%)$ and 8 (4\%) aged 30-40 and 41-50 years, respectively; the majority were bachelor degree (94, 47\%), than diploma's (52, 26\%), high school $(23,11.5 \%)$, master's degree $(17,8.5 \%)$, and $(14,7 \%)$ receiving other qualifications; and finally, their experience, in descending order of numbers, 2-5 year ranged from $(87,43.5 \%), 6-10$ years $(53,26.5 \%), 11-15$ years $(33$, $16.5 \%)$, over 15 years $(15,6 \%)$, and less than 2 years $(12,6 \%)$.

Table 2

Demographic attributes.

\begin{tabular}{|c|c|c|c|}
\hline Demography & Group & $(n=200)$ Frequency & Percentage \\
\hline \multirow[t]{2}{*}{ Gender } & Female & 17 & 8.5 \\
\hline & Male & 183 & 91.5 \\
\hline \multirow[t]{2}{*}{ Marital Status } & Married & 46 & 23 \\
\hline & Single & 154 & 77 \\
\hline \multirow[t]{3}{*}{ Age (years) } & $20-30$ & 141 & 70.5 \\
\hline & $31-40$ & 51 & 25.5 \\
\hline & $41-50$ & 8 & 4 \\
\hline \multirow[t]{5}{*}{ Educational Level } & High School & 23 & 11.5 \\
\hline & Diploma & 52 & 26 \\
\hline & Bachelors & 94 & 47 \\
\hline & Masters & 17 & 8.5 \\
\hline & Other & 14 & 7 \\
\hline \multirow[t]{5}{*}{ Years of Experience } & $<2$ & 12 & 7.5 \\
\hline & $2-5$ & 87 & 16.5 \\
\hline & $6-10$ & 53 & 26.5 \\
\hline & $11-15$ & 33 & 43.5 \\
\hline & $15+$ & 15 & 6 \\
\hline
\end{tabular}

Notes: $n$ : respondents' total number.

\subsection{Descriptive Analysis}

Table 3 shows the descriptive analysis results of each variable and item, where the means for proficiency (3.95), ICP (4.02), and OP (4.01) evolving that the majority of respondents is "agreed" upon the role of proficiency and ICP in OP.

Table 3

Descriptive analysis results

\begin{tabular}{|c|c|c|c|}
\hline Construct & Sub-constructs & Indicators & Mean \\
\hline \multirow{7}{*}{ 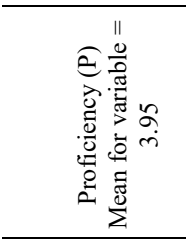 } & \multirow[t]{4}{*}{ PSC } & PSC1: organization is being affected due to incompetent staff. & 3.96 \\
\hline & & PSC2: staff achieved the purpose of being held. & 3.89 \\
\hline & & PSC3: storekeepers have the required competence. & 3.91 \\
\hline & & PSC4: storekeepers help to diagnose problems. & 3.96 \\
\hline & \multirow[t]{3}{*}{$\overline{\mathrm{PST}}$} & PST5: educating workers. & 4.01 \\
\hline & & PST6: organization intends to develop skills. & 3.98 \\
\hline & & PST7: staff training is needed. & 3.47 \\
\hline \multirow{8}{*}{ 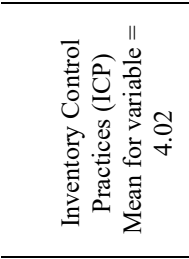 } & \multirow[t]{4}{*}{ ICS } & ICS1: most deliveries are delayed. & 4.03 \\
\hline & & ICS2: vital to determine order size for inventory. & 4.03 \\
\hline & & ICS3: always maintain buffer stock. & 4.02 \\
\hline & & ICS4: crucial items often out of stock. & 4.00 \\
\hline & \multirow[t]{4}{*}{$\mathrm{ICA}$} & ICA5: ability to improve inventory accuracy. & 4.07 \\
\hline & & ICA6: physical inventory varies from system stock. & 3.98 \\
\hline & & ICA7: handling inaccurate inventories. & 4.06 \\
\hline & & ICA8: experiencing discrepancies in stock balance. & 4.00 \\
\hline \multirow{9}{*}{ 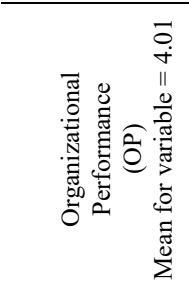 } & \multirow[t]{4}{*}{ OPC } & OPC1: cost minimization at the risk of stock-outs affects performance. & 4.08 \\
\hline & & OPC2: determine inventory optimization. & 4.03 \\
\hline & & OPC3: expired items are in stock. & 4.08 \\
\hline & & OPC4: hasty buying increases costs. & 4.09 \\
\hline & \multirow[t]{5}{*}{ OPSQ } & OPSQ5: overall quality is being achieved. & 3.36 \\
\hline & & OPSQ6: effective mechanisms improve clients' efficiency. & 3.95 \\
\hline & & OPSQ7: essential part of quality deliverance is stock handlers. & 3.93 \\
\hline & & OPSQ8: x-rays and laboratory equipment are sufficient. & 3.96 \\
\hline & & OPSQ9: bed occupancy rate (BOR) is high. & 3.95 \\
\hline
\end{tabular}

Notes: PSC: proficiency through staff competencies; PST: proficiency through staff training; ICA: inventory accuracy; ICS: inventory stocks; OPC: organizational performance cost; OPSQ: organizational performance service quality

\subsection{Assessment of Measurement Model}

Measurement model refers to validation procedure. This study performed pooled CFA and validated a second-order model (Awang, 2015). Fig. 2 depicts the assessment of unidimensionality, validity, and reliability. 


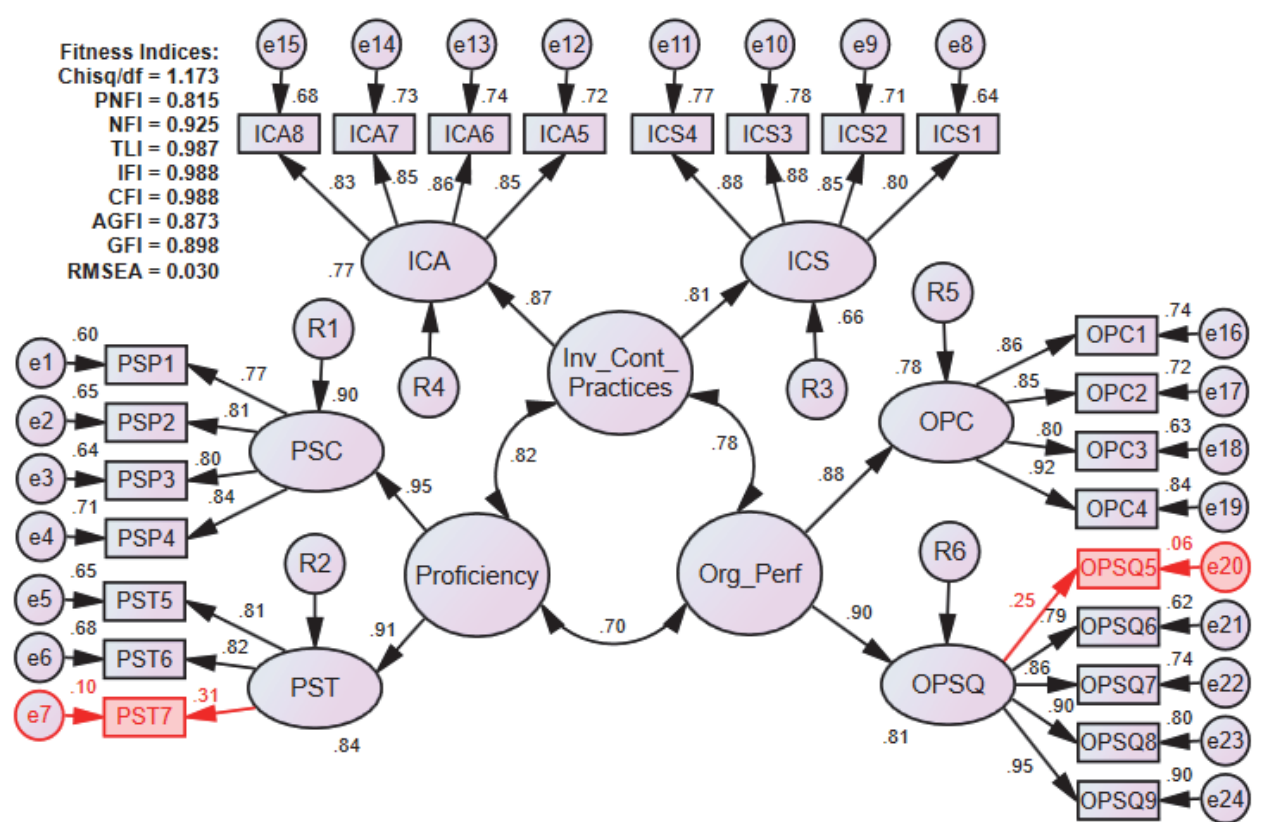

Source: Graphics of AMOS

Fig. 2. Measurement model (unidimensionality no achieved)

\subsubsection{Unidimensionality}

A set of dummy variables that explain a construct is called Unidimensionality (Hair et al., 2010). Maximum likelihood estimation (MLE) was conducted and then the items (OPSQ5 and PST7) removed as found $<0.60$ (see Fig. 3) (Hair et al., 2010). Once these two items were removed, then the factor loadings ranged from $0.768-0.951$ (see Fig. 3 and Table 5), substantiating that within a single construct there are similarities between indicators, and the unidimensionality has adequately been achieved (Hair et al., 2010).

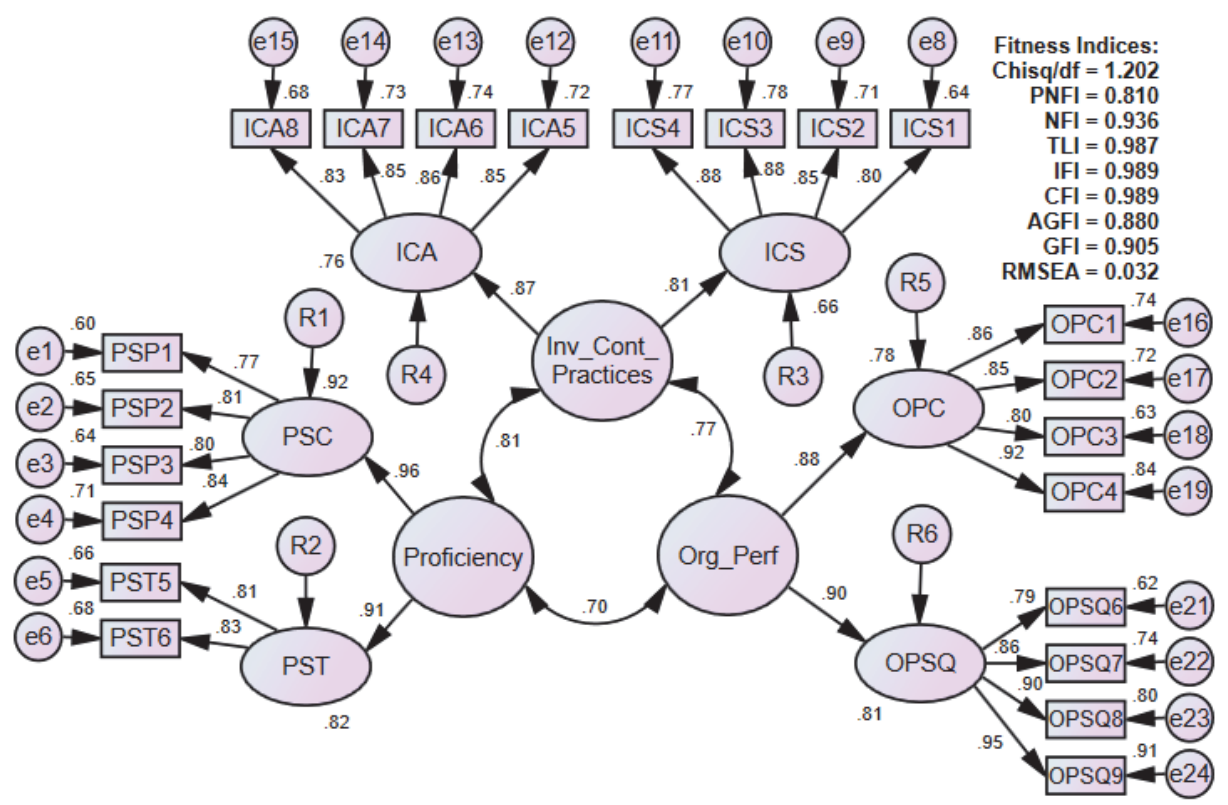

Source: Graphics of AMOS

Fig. 3. Measurement model after modification

\subsubsection{Validity}

Henseler (2012) suggested criteria (construct, convergent, and discriminant validity) were examined to validate the measurement model. 


\subsubsection{Construct Validity and Reliability}

Construct validity was measured through three goodness of-fit indices: absolute fit, incremental fit, and parsimonious fit (Hair et al., 2010). The frequent cited and recommended indices with description are shown in Table 4. According to Hair et al. (2010), selection of at least one category from each fitness index is essential to validate the measurement model. Thereby, Fig. 3 shown the fitness indices for measurement model, where Chisq $/ \mathrm{df}=1.202$, PNFI $=0.810$, NFI= $0.936, \mathrm{TLI}=0.987, \mathrm{IFI}=0.989, \mathrm{CFI}=0.989, \mathrm{AGFI}=0.880, \mathrm{GFI}=0.905$, and $\mathrm{RMSEA}=0.032$ have sufficed the recommended criterions.

Table 4

Fit-indices and its description.

\begin{tabular}{|c|c|c|c|c|c|}
\hline Type & Index & Criterion & Comments & Literature & \\
\hline Parsimonious fit & Chisq/df & $<5.0$ & Should be beyond 5.0 & Kline (2010) & \\
\hline \multirow[t]{4}{*}{ Incremental fit } & TLI & $\geq 0.90$ & $\geq 0.95$ is good & Bagozzi and Yi (1988) & \\
\hline & CFI & $\geq 0.90$ & $\geq 0.95$ is good & Hair et al. (2010) & \\
\hline & NFI & $\geq 0.80$ & $\geq 0.95$ is good & Bentler and Bonnet (1980) & \\
\hline & AGFI & $\geq 0.80$ & $\geq 0.95$ is good & Chau and $\mathrm{Hu}(2001)$ & \\
\hline \multirow[t]{3}{*}{ Absolute fit } & GFI & $\geq 0.90$ & $\geq 0.95$ is good & Jöreskog and Sorbom (1984) & \\
\hline & Chisquare & $p>0.05$ & Sensitive for sample size $>200$ & Awang (2015) & \\
\hline & RMSEA & $\leq 0.08$ & $0.05-1.00$ acceptable & Hair et al. (2010) & \\
\hline Index & \multicolumn{5}{|c|}{ Description } \\
\hline Chisq/df & \multicolumn{4}{|c|}{ Estimation process is dependent on the sample data. } & \\
\hline CFI & \multicolumn{4}{|c|}{ Assumes that all latent variables are uncorrelated and compares the sample covariance matrix with this null model. } & \\
\hline NFI & \multicolumn{4}{|c|}{ To assess the model by comparing the $\mathrm{x}^{2}$ value of the model to the $\mathrm{x}^{2}$ of the null model. } & 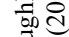 \\
\hline AGFI & \multicolumn{4}{|c|}{ Adjust the GFI based upon degree of freedom. Tend to increases with sample size. } & ¿ \\
\hline GFI & \multicolumn{4}{|c|}{ Calculate the proportion of variance that is accounted for by the estimated population covariance. } & 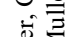 \\
\hline RMSEA & \multicolumn{4}{|c|}{$\begin{array}{l}\text { It will choose the model with the lesser number of parameters. Sensitive to number of estimated parameters in the } \\
\text { model. }\end{array}$} & 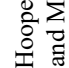 \\
\hline Chisquare & \multicolumn{4}{|c|}{ To assess the magnitude of discrepancy between the sample and fitted covariance matrices. } & \\
\hline
\end{tabular}

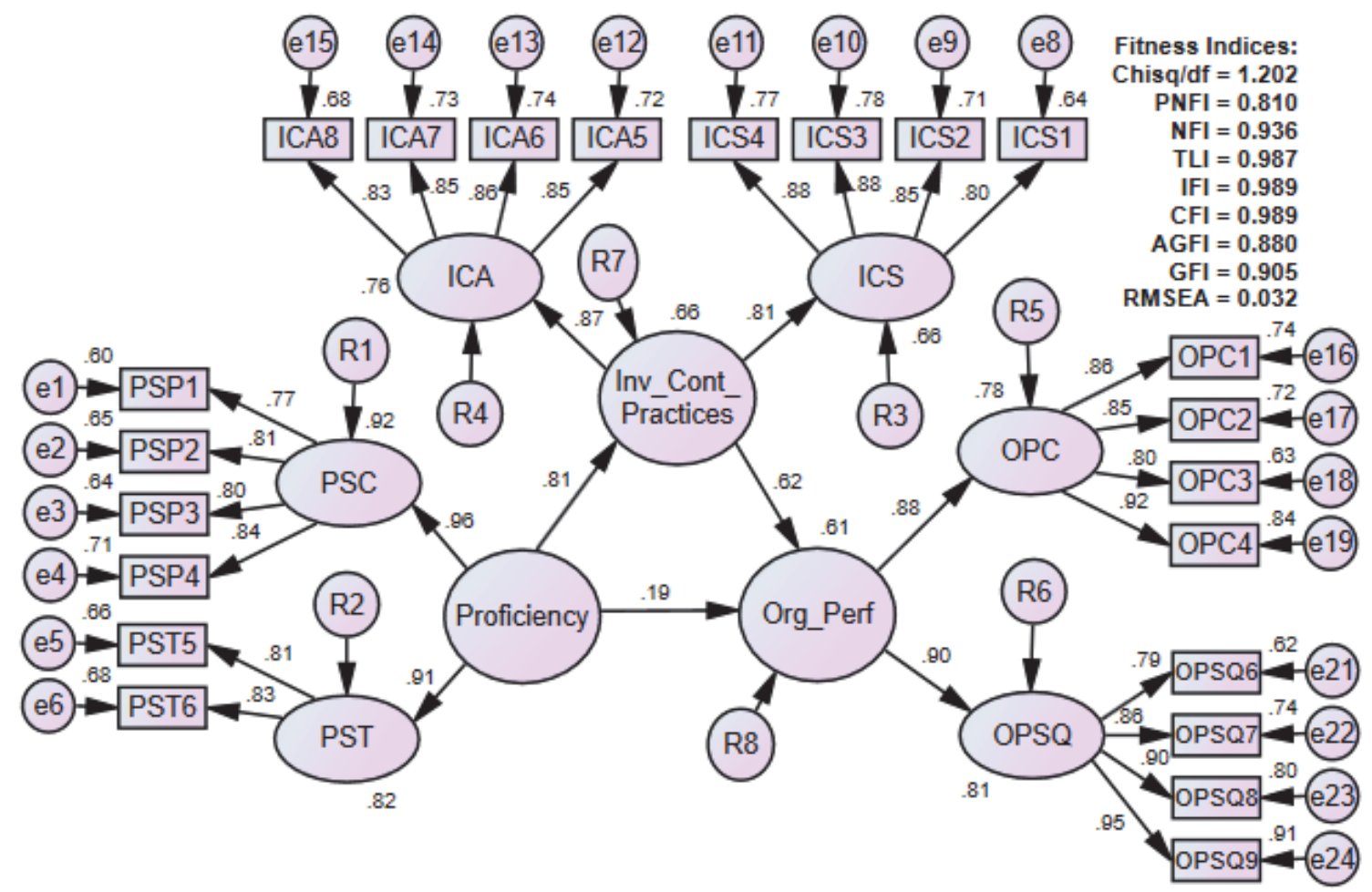

Source: Graphics of AMOS

Fig. -4. Structural Equation Modeling (SEM)

Likewise, Table 5 demonstrates the reliability test through Cronbach alpha (a) (ranged $0.903-0.941,>0.70)$ and Composite Reliability (CR) (ranged $0.831-0.829>0.70$ ) (Hair et al., 2010). The construct validity and reliability $>0.70$ indicates that the model is sufficiently error-free. 
Table 5

Summarized results of measurement model

\begin{tabular}{|c|c|c|c|c|c|}
\hline Constructs & Items and Sub-Constructs & $a$ & Std $\beta$ & $\mathbf{C R}$ & AVE \\
\hline \multirow{8}{*}{ 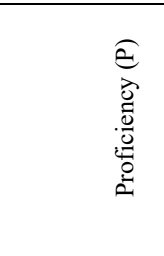 } & PSC & \multirow{8}{*}{0.903} & 0.969 & \multirow{8}{*}{0.929} & \multirow{8}{*}{0.867} \\
\hline & PSC1 & & 0.768 & & \\
\hline & PSC2 & & 0.805 & & \\
\hline & PSC3 & & 0.803 & & \\
\hline & PSC4 & & 0.847 & & \\
\hline & PST & & 0.894 & & \\
\hline & PST4 & & 0.815 & & \\
\hline & PST5 & & 0.823 & & \\
\hline \multirow{10}{*}{ 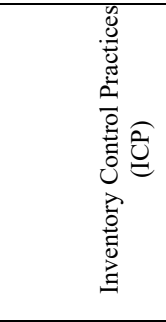 } & ICS & \multirow{10}{*}{0.923} & 0.848 & \multirow{10}{*}{0.831} & \multirow{10}{*}{0.711} \\
\hline & ICS1 & & 0.804 & & \\
\hline & ICS2 & & 0.848 & & \\
\hline & ICS3 & & 0.878 & & \\
\hline & ICS4 & & 0.878 & & \\
\hline & ICA & & 0.835 & & \\
\hline & ICA5 & & 0.848 & & \\
\hline & ICA6 & & 0.86 & & \\
\hline & ICA7 & & 0.857 & & \\
\hline & ICA 8 & & 0.822 & & \\
\hline \multirow{10}{*}{ 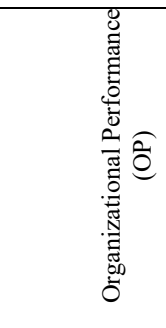 } & OPC & \multirow{10}{*}{0.941} & 0.882 & \multirow{10}{*}{0.885} & \multirow{10}{*}{0.794} \\
\hline & OPC1 & & 0.858 & & \\
\hline & OPC2 & & 0.851 & & \\
\hline & OPC3 & & 0.796 & & \\
\hline & OPC4 & & 0.919 & & \\
\hline & OPSQ & & 0.901 & & \\
\hline & OPSQ6 & & 0.785 & & \\
\hline & OPSQ7 & & 0.863 & & \\
\hline & OPSQ8 & & 0.895 & & \\
\hline & OPSQ9 & & 0.951 & & \\
\hline
\end{tabular}

Source: Output of AMOS

\subsubsection{Convergent Validity}

Hair et al. (2010) suggested that this validity could be tested by calculating AVE with recommended value of $\geq 0.50$. Table 5 shows AVE results that satisfy all constructs (AVE ranged 0.711 to 0.867 ).

\subsubsection{Discriminant validity}

Hair et al. (2010) indicated that the discriminant validity examines the latent constructs for differentiates. The diagonal values in Table 5 are higher as compare to row and column values; besides, the correlation is less than 0.85 (Awang, 2015). The results adequately satisfied the test assumptions.

\section{Table 6}

Summary of discriminant validity

\begin{tabular}{lccc}
\hline Construct & OP & Proficiency & ICP \\
\hline OP & 0.891 & & 0.931 \\
Proficiency & 0.696 & 0.815 & 0.843 \\
ICP & 0.775 & & 0 \\
\hline
\end{tabular}

Source: Output of AMOS

\subsubsection{Test of Normality}

According to Awang (2015), normality test evaluates skewness and kurtosis, with recommended values between -1.0 and +1.0 . The results fell within the recommended range with sufficiently sized sample of 200 . Hence, the data is considered acceptable for SEM due to its normal distribution.

\subsection{Structural Equation Modeling (SEM)}

\subsubsection{Testing the Direct Hypotheses}

Three direct hypotheses were tested in SEM for which Table 7 demonstrating that proficiency predicts ICP and OP significantly with positive effect. Likewise, ICP predicts OP significantly with positive effect. Thus, hypotheses H1, H2, and $\mathrm{H} 3$ are supported. Additionally, the results are evident that ICP has stronger effect on OP than of proficiency. 
Table 7

Direct hypotheses (analysis of structural paths)

\begin{tabular}{|c|c|c|c|c|}
\hline Hypothesis & Path & Std $\beta$ & S.E & C.R \\
\hline H1 & ICP $\leftarrow$ Proficiency & $0.817 * * *$ & 0.096 & 7.972 \\
\hline $\mathrm{H} 2$ & $\mathrm{OP} \leftarrow$ Proficiency & $0.682 * * *$ & 0.095 & 7.087 \\
\hline $\mathrm{H} 3$ & $\mathrm{OP} \leftarrow \mathrm{ICP}$ & $0.779 * * *$ & 0.110 & 7.819 \\
\hline
\end{tabular}

Notes: $* * *, p<0.001$

Source: Output of AMOS

\subsubsection{Testing the Hypothesis of Mediation (H4)}

The mediation assessment for hypothesis (H4) examined the direct effect and indirect effect (through mediator). Table 8 demonstrating that all the direct effects (path c, a, and b) are positively significant. According to Awang (2015), this significance is essential. After entering the mediator (ICP) in the model, the path $c^{\prime}$ reduced to 0.191 that proves mediation occurs (Field, 2013). Further, there is full mediation as the path $c^{\prime}$ ' is no longer significant (Awang, 2015). Thus, the hypothesis H4 is supported as the mediation of ICP is proven.

Table 8

Mediation assessment for hypothesis $\mathrm{H} 4$

\begin{tabular}{|c|c|c|c|c|c|}
\hline & Path & Path & Std $\beta$ & S.E & C.R \\
\hline \multirow{4}{*}{$\mathrm{H} 4$} & $\mathrm{c}$ & OP $\leftarrow$ Proficiency & $0.682 * * *$ & 0.095 & 7.087 \\
\hline & $\mathrm{a}$ & $\mathrm{ICP} \leftarrow$ Proficiency & $0.815 * * *$ & 0.091 & 8.399 \\
\hline & $\mathrm{b}$ & $\mathrm{OP} \leftarrow \mathrm{ICP}$ & $0.619 * * *$ & 0.185 & 3.763 \\
\hline & $c^{\prime}$ & op $\leftarrow$ Proficiency & $0.191(\mathrm{~ns})$ & 0.159 & 1.268 \\
\hline
\end{tabular}

Notes: (ns), Not significant; $* * * \mathrm{p}<0.001$

\subsubsection{Results of Bootstrapping (Hypothesis H4)}

Preacher and Hayes (2008) suggested bootstrapping technique was also analyzed, which is broadly used for mediation assessment. Table 9 shows the indirect effect is statistically significant and $\operatorname{Std} \beta=0.139$, 95 percent boot CI: (LL= 0.184 , UL $=1.365$ ), where 0 does not straddle between LL and UL. Thus, the results are establishing the mediating role of "ICP" and supporting the hypothesis $\mathrm{H}_{4}$. Likewise, the direct effect is insignificant that suggests the full mediation in the relationship between proficiency and OP.

Table 9

Bootstrapping results for hypothesis $\mathrm{H} 4$

\begin{tabular}{cccccc}
\hline & Path & DE $($ Std $\boldsymbol{\beta})$ & IE $($ Std $\boldsymbol{\beta})$ & LL & UL \\
\hline $\mathrm{H} 4$ & Proficiency $\rightarrow \mathrm{ICP} \rightarrow \mathrm{OP}$ & $0.201(\mathrm{~ns})$ & $0.530^{* *}$ & 0.184 & 1.365 \\
\hline
\end{tabular}

Notes: ns, Not significant; **p $<0.05$; IE, Indirect Effect; DE, Direct Effect

\subsection{Coefficient of determination $\left(R^{2}\right)$}

The coefficient of determination $\left(R^{2}\right)$ of model is 0.61 that indicates, proficiency and ICP are substantially predicting 61 percent to the OP (Cohen, 1988).

\subsection{Effect size $\left(f^{2}\right)$}

The effect size evaluates the effect of a latent exogenous construct on a latent endogenous construct. The effect size of ICP on OP is large (0.36). Cohen (1988) suggested the effect size is large if greater than 0.35 , medium if greater than 0.15 , and small if greater than 0.02 . It could be calculated through $f^{2}=\left(R^{2}\right.$ included $-R^{2}$ excluded $) /\left(1-R^{2}\right.$ included $)$ (Hashmi et al., 2020a;b).

\section{Discussion}

This study validated a second-order model. The findings found positive and significant effect between proficiency, ICP, and OP, which means that the increased level of proficiency and ICP increase the level of OP, and these constructs are proportionate to each other. Further, the ICP significantly mediates the relationship between proficiency and OP, and the mediation type was full mediation. The findings are consistent with the findings of Hashmi et al. (2020a;b).

\section{Research contribution}

The public healthcare is critical and affected the most. Thereby, this research was required and integrated a second-order model. The model was developed using RBV Theory. This study contributes to the RBV theory and body of related 
literature. Besides, this research theoretically contributed to the mediating role of ICP in proficiency and OP. The findings are useful for government body and organizations managing mega-structured inventories like public and private healthcare in shaping their regulations. Additionally, the dimensions of this study can guide the public sector to shape their policies to improve their grey areas.

\section{Conclusion}

This study carried-out from the province of Punjab and at different healthcare facilities, poor house-keeping constrained the researcher's access to documented records. The findings recommend that, for enhanced proficiency, efficient inventory control, and better performance, the skill enhancement programs are necessarily required. Future researchers can determine the procurement functions and its implications on organizational performance.

\section{References}

Andrews, R., Boyne, G., \& Mostafa, A. M. S. (2017). When bureaucracy matters for organizational performance: Exploring the benefits of administrative intensity in big and complex organizations. Public Administration, 95(1), 115-139.

Attom, B. E. (2013). The impact of information communication technology (ICT) on business Growth strategies of Small and Medium-Scale Enterprises (SMEs) in the Awutu-Senya East Municipality of Central Region of Ghana. Asian Journal of Business and Management, 3(2), 13-28.

Awang, Z. (2015). SEM made simple. Bangi: MPWS Rich Publication.

Bagozzi, R. P., \& Yi, Y. (1988). On the evaluation of structural equation models. Journal of the Academy of Marketing Science, 16(1), 74-94.

Bentler, P. M., \& Bonett, D. G. (1980). Significance tests and goodness-of-fit in analysis of covariance structures. Psychological Bulletin, 88(3), 588-606. Available at: https://doi.org/10.1037/0033-2909.88.3.588.

Chau, P. Y. K., \& Hu, P. J. H. (2001). Information technology acceptance by individual professionals: A model comparison approach. Decision Sciences, 32(4), 699-719.Available at: https://doi.org/10.1111/j.1540-5915.2001.tb00978.x.

Cohen, J. (1988). Statistical power analysis for the behavioral sciences (2nd ed.). Hillsdale, NJ: Lawrence Erlbaum Associates.

Creswell, J. W. (2014). Research design: Qualitative, quantitative and mixed methods approaches (4th ed.). Thousand Oaks: SAGE Publication Inc

Field, A. (2013). Discovering Statistics using SPSS, 4th edn. London: SAGE.

Hair, J. F. J., Black, W. C., Babin, B. J., \& Anderson., R. E. (2010). Multivariate Data Analysis. A global perspective. (7th Ed.). USA: Prentice Hall.

Hashmi, A. R., Amirah, N. A., \& Yusof, Y. (2020a). Organizational performance with disruptive factors and inventory control as a mediator in public healthcare of Punjab, Pakistan. Management Science Letters, 11(1), 77-86. doi: $10.5267 /$ j.msl.2020.8.028.

Hashmi, A. R., Amirah, N. A., \& Yusof, Y. (2020b). Structural Equation Modeling: Mediation of integrated systems in supply chain management practices and public healthcare performance. International Journal of Management and Sustainability, 9(3), 148-160. doi: 10.18488/journal.11.2020.93.148.160.

Henseler, J. (2012). Why generalized structured component analysis is not universally preferable to structural equation modeling. Journal of the Academy of Marketing Science, 40(3), 402-413. Available at: http://doi.org/10.1007/s11747014-0403-8.

Hooper, D., Coughlan, J., \& Mullen, M. (2008). Structural equation modelling: guidelines for determining model fit. Articles, 2.

Jöreskog, K., \& Sörbom, D. (1993). LISREL 8: Structural equation modeling with the SIMPLIS command language. Chicago, IL.: Scientific Software International Inc.

Kline, R. B. (2010). Principles and practice of structural equation modelling (4th ed.). New York: The Guilford Press.

Preacher, K. J., \& Hayes, A. F. (2004). SPSS and SAS procedures for estimating indirect effects in simple mediation models. Behavior Research Methods, Instruments, \& Computers, 36(4), 717-731.Available at: https://doi.org/10.3758/bf03206553.

Pritchard, B., Gracy, C., \& Godwin, M. (2010). The impacts of supermarket procurement on farming communities in India: Evidence from rural Karnataka. Development Policy Review, 28(4), 435-456. Available at: https://doi.org/10.1111/j.1467-7679.2010.00491.x.

Rashid, A. (2016). Impact of inventory management in downstream chains on customer satisfaction at manufacturing firms. International Journal of Management, IT and Engineering, 6(6), 1-19.

Rashid, A. (2020). The effect of disruptive factors on organizational performance: The mediating role of inventory control at the Department of Health in Punjab, Pakistan (Unpublished doctrol dissertation). Universiti Sultan Zainal Abidin, Malaysia.

Rashid, A., \& Amirah, N. (2017). Relationship between poor documentation and efficient inventory control at Provincial Ministry of Health, Lahore. American Journal of Innovative Research and Applied Sciences, 5(6), 420-423.

Rashid, A., Amirah, N., \& Yusof, Y. (2019). Statistical approach in exploring factors of documentation process and hospital performance: A preliminary study. American Journal of Innovative Research and Applied Sciences, 9(4), 306-310. 
Rehman, S.-u., Mohamed, R., \& Ayoup, H. (2019). The mediating role of organizational capabilities between organizational performance and its determinants. Journal of Global Entrepreneurship Research, 9(1), 1-23.

Samuel, I. S., \& Ondiek, O. (2014). Inventory management automation and the performance of supermarkets in Western Kenya. International Journal of Research in Management \& Business Studies, 3(5), 1-12.

Shah, R., \& Shin, H. (2007). Relationships among information technology, inventory, and profitability: An investigation of level invariance using sector level data. Journal of Operations Management, 25(4), 768-784. Available at: https://doi.org/10.1016/i.jom.2007.01.011.

Shibin, K., Gunasekaran, A., \& Dubey, R. (2017). Explaining sustainable supply chain performance using a total interpretive structural modeling approach. Sustainable Production and Consumption, 12, 104-118.Available at: https://doi.org/10.1016/j.spc.2017.06.003.

Wernerfelt, B. (1984). A resource-based view of the firm. Strategic Management Journal, 5, 171-180.

Worthington, R. L., \& Whittaker, T. A. (2006). Scale development research: A content analysis and recommendations for best practices. The counseling Psychologist, 34(6), 806-838.Available at: https://doi.org/10.1177/0011000006288127.

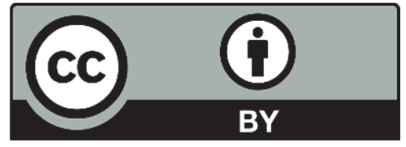

(C) 2021 by the authors; licensee Growing Science, Canada. This is an open access article distributed under the terms and conditions of the Creative Commons Attribution (CC-BY) license (http://creativecommons.org/licenses/by/4.0/). 